\title{
MC-ICP-MS U-series dating of the Panxian Dadong Paleolithic site at Guizhou, Southern China
}

\author{
X.C. $\mathrm{CHE}^{1,5^{*}}$, J.X. ZHAO ${ }^{2}$, G.J. $\mathrm{SHEN}^{3}$, B. CAO ${ }^{4}$, H.Y. \\ $\mathrm{SUN}^{1}$, D.Y. $\mathrm{LIU}^{1}$ \\ ${ }^{1}$ Beijing SHRIMP Center, Institute of Geology, Chinese \\ Academy of Geological Sciences, Beijing, 102206, \\ China \\ ${ }^{2}$ Radiogenic Isotope Facility, School of Earth \& \\ Environmental Sciences, The University of Queensland, \\ Brisbane, QLD, 4072, Australia \\ ${ }^{3}$ College of Geographical Sciences, Nanjing Normal \\ University, Nanjing, 210023, China \\ ${ }^{4}$ Guizhou Cultural Archaeological Institiute, Guizhou, \\ 550003, China \\ ${ }^{5}$ School of Earth and Space Sciences, University of Science \\ and Technology of China, Hefei, 230026, China \\ *Corresponding author: cxc@bjshrimp.cn
}

Panxian Dadong is located in the Liupanshui area in the western part of Guizhou Province. In 1990, Panxian Dadong was first discovered to have human activities. From 1992 to 2000, Dadong carried out six excavations in cooperation with Chinese and foreign scientists. Four hominin teeth fossils, abundant chipped stones and animal remains were recovered. In comparison with the world's mid-late Pleistocene humans, Homo erectus and modern humans, it is found that four hominin teeth fossils in Panxian Dadong are between the Homo erectus and the early Homo sapiens in morphological characteristics, and have shown the variability of modern humans represents the type of transition of early Homo sapiens to modern Humans.

The identical, within uncertainties, Dadong Paleolithic site age of 130-300 Ka have been reported by several studies. U-Series dating of carbonate is a crucial method to accurately determine the age of Paleolithic cave sites within $500 \mathrm{Ka}$. In this study, U-series dating was carried out using the MC-ICP-MS in Radiogenic Isotope Facility at the University of Queensland, the corrected age of the fourth flowstone layer was $379 \pm 8 \mathrm{Ka}, 343 \pm 106 \mathrm{Ka}$, and the age of the stalagmites at the bottom of the digging hole inside of the Dadong was $406 \pm 78 \mathrm{Ka}, 368 \pm 135 \mathrm{Ka}$. A flowstone outside the entrance of Dadong obtains $440 \pm 34 \mathrm{Ka}$. Those above samples are almost in the same horizontal layer inside of the Cultural deposit. Therefore, we suggest that the age of the Panxian Dadong hominin should thus be at least 400 $\mathrm{Ka}, 100 \mathrm{Ka}$ older than the previous studies. 